\title{
Addressing the Need to Reform Construction Public Procurement in Ireland through the Implementation of Building Information Modelling
}

\author{
Barry McAuley \\ Technological University Dublin, barry.mcauley@tudublin.ie \\ Alan Hore \\ Technological University of Dublin, alan.hore@tudublin.ie \\ Roger West \\ Trinity College, rwest@tcd.ie
}

See next page for additional authors

Follow this and additional works at: https://arrow.tudublin.ie/beschreccon

Part of the Construction Engineering and Management Commons

\section{Recommended Citation \\ McAuley, B., Hore, AV., West, RP and Kehily, D (2012) Addressing the Need to Reform Construction Public Procurement in Ireland through the Implementation of Building Information Modelling, Proceedings of the 1st ASEA-SEC International Conference on Research, Development and Practice in Structural Engineering and Construction, Perth Western Australia, 28th Nov - 2nd Dec 2012 https://doi.org/10.21427/a98p-ae33}

This Conference Paper is brought to you for free and open access by the School of Surveying and Construction Management at ARROW@TU Dublin. It has been accepted for inclusion in Conference papers by an authorized administrator of ARROW@TU Dublin. For more information, please contact arrow.admin@tudublin.ie, aisling.coyne@tudublin.ie,gerard.connolly@tudublin.ie.

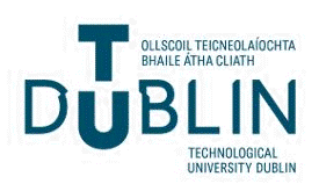


Authors

Barry McAuley, Alan Hore, Roger West, and Dermot Kehily

This conference paper is available at ARROW@TU Dublin: https://arrow.tudublin.ie/beschreccon/35 


\title{
ADDRESSING THE NEED TO REFORM CONSTRUCTION PUBLIC PROCUREMENT IN IRELAND THROUGH THE IMPLEMENTATION OF BUILDING INFORMATION MODELLING
}

\author{
Barry Mcauley ${ }^{1, a}$, Alan Hore ${ }^{1, b}$, Roger West ${ }^{2}$ and Dermot Kehily ${ }^{1, c}$ \\ ${ }^{1}$ School of Real Estate and Economics, Dublin Institute of Technology, Dublin, Ireland \\ E-mail: ${ }^{a}$ barrymcauley@gmail.com, ${ }^{b}$ alan.hore@dit.ie, ${ }^{c}$ dermot.kehily@dit.ie \\ ${ }^{2}$ School of Civil Engineering and Environmental Engineering, Trinity College Dublin, \\ College Green, Dublin, Ireland \\ E-mail: rwest@tcd.ie
}

The Irish AEC Sector is facing one of its most uncertain and challenging periods and will see major cuts in all areas of the economy in 2012. Despite this the Irish Government has announced a number of large capital expenditure investments which have resultantly become a lifeline to a struggling construction industry. In order to compete within the public works sector AEC businesses must operate within the Governments Capital Works Management Framework. The objectives of the framework include achieving cost certainty, value for money and more effective delivery and appropriate risk sharing. The framework remains an area of contention and it has yet to be seen if it has provided a more efficient way of doing business. In order for the Irish Government client to procure more cost effective projects and achieve an estate that is smarter and better equipped to face a low carbon future, it is recommended by the authors, that the Irish Government move towards the mandatory use of Building Information Modelling on public works projects. The data collation methodology for this paper included an in-depth questionnaire survey that was compared with two international industry reports, from recent CITA BIM Workshops, that explored setting an aligned top down strategy and the cultural, process change management, required for BIM Implementation. Despite the general understanding that BIM could play a key role in reforming the Irish public procurement sector, it is highly unlikely the Irish Government will implement BIM in the short term due to other more immediate priorities that require attention in the Irish AEC sector.

Keywords: Building information modelling, Public procurement, Government contracts, Cultural change, Process change management.

\section{Introduction}

The Irish construction sector has seen a sharp decline in output since 2007, with initial forecasts of recovery not expected to happen until 2014. This has resulted in a sector that was once responsible for $25 \%$ GNP now free falling to a predicted $6 \%$ GNP by 2012 , as detailed by Nuggent (2012). Within these challenging times, the strong majority of competitive construction work comes from the public works sectors, in which a Capital Works Management Framework (CWMF) was introduced in 2007 as a response to significant cost overruns on major publically procured construction projects. The aim of the CWMF is to ensure that there is an integrated methodology and a consistent approach to the planning, management and delivery of public capital works projects, with the objectives of greater cost certainty, better value for money and more efficient project delivery. Notably within the CWMF the Irish government published a new suite of public sector contracts. These new forms aimed to support the certainty of outcome in terms of cost, quality and programme through the introduction of fixed price contracts. Despite their introduction there has been no evidence that they have delivered the results intended by the Irish government.

In order for the Irish Government to successfully guarantee a more reliable method

Research, Development, and Practice in Structural Engineering and Construction Edited by Vanissorn Vimonsatit, Amarjit Singh, and Siamak Yazdani

Copyright (C) 2013 by Research Publishing Services :: www.rpsonline.com.sg ISBN: 978-981-08-7920-4 :: doi: 10.3850/978-981-08-7920-4_AAE-15-0383 
of cost certainty and greater value, it is recommended by the authors, that the Irish Government move towards the mandatory use of Building Information Modelling (BIM) on public works projects. This could potentially ensure that public clients would ultimately commission assets that are smarter and better equipped to face a low carbon economy, with associated reductions in delivery and carbon emissions.

\section{Methodology}

The authors' primary data collation methodology involved an extensive survey that targeted a cross section of the Irish AEC sector, in order to gauge the level of support for the introduction of BIM to assist in achieving the vision of the CWMF.

The survey results were compared with the results of two industry reports prepared by the authors from a current suite of Construction IT Alliance (CITA) BIM workshops in 2012. These workshops are the result of a unique collaboration between CITA and a number of AEC representative institutions within Ireland, who have come together through the commissioning of ten BIM Workshops in 2012, with the intention of promoting BIM within the Irish $\mathrm{AEC} / \mathrm{FM}$ industry.

This paper will also review the use of BIM initiatives that have been carried out to address public reform internationally and relate how those experiences can be applied to Ireland.

\section{Literature Review}

The authors conducted a review of journal papers, professional publications and research articles. The literature review focused on the three main areas detailed below, in order to establish the benefits of using BIM to reform public procurement in Ireland:

- Addressing the need to reform public procurement in Ireland.
- Global implementation and barriers of BIM.

- Cultural, process change management, required for BIM Implementation

\subsection{Addressing the Need to Reform Public Procurement in Ireland}

Ireland remains one of the more depressed operating environments for the construction sector and the potential for defaults remain relatively high compared to average default rates over the last 10 years (Henstridge, 2011). In response to this the Irish Government has announced a number of large capital investments to be initiated over the next few years. These investments include amongst other things a 1.5 billion programme in 2012 to provide new schools and extend existing schools across the country. These public works projects have become a lifeline to struggling businesses in the Irish AEC sector. In order to compete within the public works sector potential firms must operate within the Governments public works contracts. Fogarty (2009) outlined concerns for contractors operating within these contracts; these include the transfer of risk from the employer to the contractor and restrictions that exist for a contractor's ability to claim for amounts over the initial contract sum. Following the collapse of the 'Celtic Tiger' and, in its wake, the propping-up of the Irish financial system, some commentators have expressed a new, fairer, more equitable and collaborative solution should be pursued in the Irish construction industry to deliver public sector projects (Wren, 2011).

This collaborative approach can be achieved through the re-drafting of the public works contracts to include the use of BIM technologies. The role of the Irish Government will be critical if the implementation of BIM is to become a reality and must play a major driver in this process, as well as, review current BIM initiatives and barriers within internationally public sector procurement (McAuley et al., 2012a). 


\subsection{Global Implementation and Barriers of BIM}

BIM is not just a technology but should be seen as a catalyst for a deeper process. To facilitate this process contractual changes in the building industry require a more integrated approach (Hannele, 2012). BIM as outlined by Pike Reseacrh (2012) represents one of the most important breakthroughs in building design technology over the last decade, with annual worldwide revenue for BIM products and services solutions to grow from $\$ 1.8$ billion in 2012 to almost $\$ 6.5$ billion in 2020 . The revolution of BIM across the global construction world continues to grow and must result in Ireland adopting a similar methodology or face being left behind and unable to compete in foreign markets (McAuley et al., 2012b).

In order to participate in this lucrative market, Ireland must follow the example of various countries including the USA, Finland, Norway, Denmark, UK, Germany, Singapore and Korea, who are all currently in the process of developing BIM guidelines. Perhaps most encouraging to the Irish Public Sector, is the move by the UK public construction sector, towards the legal implementation of BIM by 2016. There is a plan for a phased five-year development that projects will be required to use BIM tools and techniques from 2016 within the UK.

In order for Ireland to create a similar frame work there are a number of obstacles to be addressed in the form of both legal and technical categories. With the increase in the utilization of BIM in the construction industry, it has become clear that there is some legal uncertainty in dealing with this technology (Douglas et al., 2012). The same authors express other problems which include, who will own the model at the completion of the project, the right to rely on the model and the information in it, shifting of risk between parties involved in the construction process and the added cost of BIM. In order for the UK to achieve a Level 2 BIM standard, which is a BIM File Based Collaboration and Library Management, there is little change required to the fundamental building blocks of copyright law, contracts or insurance. This is encouraging to an Irish perspective, as our current contracting arrangements are not considerably different to the UK (McAuley et al., 2012a).

\subsection{Cultural, Process Change Management, Required for BIM Implementation}

BIM effectively requires significant changes in the way construction businesses work at almost every level within the building process and requires not only learning new software applications, but also how to reinvent the workflow, how to train staff and assign responsibilities. (Arayici et al., 2011). BIM represents a sea change to the design process and how we prepare our firms for this shift will have everything to do with our future success. For many, rapid change can be difficult, and nearly all culture changes take time (Bachman, 2009). If $\mathrm{BIM}$ is to be the catalyst in reforming the Irish public procurement sector, the industry must learn by looking at other jurisdictions where there has been a cultural shift and new innovative ways of process change management adopted.

This change can be achieved through the establishment of BIM committees or research institutions, which can then provide the support needed to make the cultural shift. As outlined by Wong et al (2009) VTT in Finland, Rambøll in Denmark and SINTEF in Norway are some of the major research organizations in BIM in their respective countries. The establishment of the Construction Client Group, as well as, the BIM academy has seen the UK put the necessary support in place to ensure its 2016 target is achieved.

Ireland needs to follow the examples of these countries and learn from their mistakes and success, while ensuring an adequate support structure is in place to 
accommodate the change in culture and processes in regards to how we effectively do business. Despite Ireland been in its infancy in promoting BIM, the Irish Government has started to take notice. This was evident from a recent delegation of CITA who were invited to give a presentation to the GCCC on the merits of adopting BIM.

\section{Primary Research}

\subsection{BIM Survey}

An online questionnaire was created with 21 questions. There were a total of 90 phone calls and emails sent out to a various mix of companies within the CITA membership database, as well as posting the survey link to the CITA BIM working group webpage, which represents the largest special interest working group on BIM in Ireland. This generated a total of 86 responses from a mix of small to large enterprises. The response from each profession is shown in Table 1.

\begin{tabular}{lr}
\hline Sector & $\%$ \\
\hline Achitecture & $26.5 \%$ \\
Quantity Surveying & $13.3 \%$ \\
Contractors & $13.3 \%$ \\
Engineering & $14.5 \%$ \\
Consulting & $9.6 \%$ \\
Suppliers & $1.2 \%$ \\
Facilities Managers & $6.0 \%$ \\
Training and Education & $10.8 \%$ \\
IT Vendors/Business Service & $4.8 \%$ \\
\hline
\end{tabular}

\subsubsection{Overview}

The questions were formatted in consideration of the literature review, and, statements and claims as put forward by the authors in previous publications (McAuley et al., $2012 \mathrm{a} \& \mathrm{~b}$ ) advocating the implementation of BIM on public works projects as a tool to ensure enhanced value for money and low carbon construction in Ireland.

\subsubsection{Survey Analysis}

The questionnaire was broken into four different sections, in order to properly address areas of the literature research that were deemed relevant. The first part of the questionnaire explored the level of BIM awareness in Ireland, with $52 \%$ of respondents aware of BIM and $43 \%$ currently using it.

The second part of the survey established that despite the majority of respondents using 3D drawings there are only $15 \%$ using 3D drawings with intelligent data i.e. Level 2 BIM. This would suggest that despite $43 \%$ of respondents saying that they currently use BIM, there is possibly a lack of understanding as to the fact that BIM is a process and not just 3D drawings. This issue is further echoed through $80 \%$ of the respondents in the survey claiming that the industry is not clear enough on what BIM is yet. However, encouragingly $89 \%$ state that they are or will be using BIM within 5 years and $67 \%$ of the respondents state that it will be of high importance to the industry in 5 years. There is a strong believe that by investing now in BIM will result in a stronger foothold in the future, as BIM will form the basis of major contract works.

The third part of the questionnaire established that $43 \%$ of respondents have operated within the GCCC forms of contract. A strong majority either agrees or stay neutral to the fact that the contracts ensure greater cost certainty; rebalance of risk and efficient delivery of projects. However, there is a split in regards to the question of whether these contracts provide value for money. Though value seems to exist in the industry through reduced tenders, it is suggested by some respondents that this is due to economic circumstances rather than the effects of the new GCCC contracts. The approach to follow the UK in mandating BIM as a more efficient way of achieving the government's aims is advocated by the authors, with $62 \%$ of the survey in total agreement. There is up to $69 \%$ of the survey who claim that BIM can ensure enhanced cost certainty, better rebalance of 
risk, improved efficient delivery of projects and value for money. There is an understanding by some respondents, in that as the Irish government has previously followed closely behind the UK system and is also strongly linked to the UK through the vast majority of Irish AEC firms doing business in the UK, that BIM must be an eventuality. There is a concern from a number of the respondents that BIM may restrict the competition and its introduction may give rise to larger practices getting more than their fair share of government work, as they have greater ability to take on the infrastructural investment required for BIM. A solution put forward within the survey response to this is to provide a rapid up skilling and tooling programme where $1 \%$ is taken of every current and upcoming project and put towards training, hardware and software.

The final part of the survey explored the role in which BIM can play in ensuring a smarter and better equipped public estate. $54 \%$ of the respondents indicated that BIM can play a significant role in ensuring Ireland meets its 2018 carbon targets, with $47 \%$ of the survey claiming that BIM can also play a significant role in ensuring Ireland can meet its retrofitting existing stock carbon targets. There are also $57 \%$ of the respondents who indicate that BIM can be a significant Facilities Management tool in managing the Government's estate. This ultimately depends on funding and initiatives put in place by the Irish Government.

\subsection{CITA BIM Workshops}

A suite of BIM workshops where commissioned in 2012 which are to be primarily hosted by CITA. These workshops were sponsored by professional institutions with the overreaching aim of promoting BIM within Ireland.

\subsubsection{Overview}

The two workshops in questions where based around setting an aligned top down strategy and the cultural, process change management, required for BIM Implementation There was over 100 professionals involved within these two workshops in which a number of questions where addressed in a round table discussion.

\subsubsection{Roundtable Discussion}

There was a resounding agreement that the Irish Government should follow the UK Government's decision in mandating the use of BIM on public sector projects. The legal mandating of BIM can be a driver to make the industry more technically aware and could provide the tools for Irish Construction firms to compete in International markets. There were concerns noted in regards to the impact that the legal mandating of BIM may have on SME's, with the Government possibly reluctant to be seen discriminating against these companies.

There are a number of cultural habits within the Irish AEC/ FM Industry which have been reinforced from the introduction of the GCCC forms of contracts. These include amongst other things a hostile environment consisting of conciliation and arbitration with a resulting large risk of insolvency. While BIM is not the solution to all of the industry's problems, it will significantly help reduce fragmentation in the industry. In order for BIM to be successfully implemented and a shift towards process change management, there must be an assigned independent BIM project manager. To ensure there is a shift in cultural habits as well as eliminating the culture of conflict currently in the industry, it is essential that there must be agreements made between different parties working on the model in which will help to address possible litigation. In order for BIM to be a reality the Government must embrace more collaborative contracts.

\section{Conclusion}

The triangulation of the primary research shows strong evidence that there is a strong believe within the Irish AEC sector that we should follow the UK's move towards the 
mandating of BIM. This can ensure that we are forced out of - our comfort zone and can further result in reducing inefficiencies in the way we do business, which will pass on savings to the client in the capital cost of the project both in the short and long term. There are a number of concerns raised with this process, including alienating SMEs and creating a monopoly in the public sector where only large enterprises can compete. There needs to be smarter cost effective ways to enable all companies to adopt BIM and that awarding of multiple contracts to any one firm is limited over a given period of time to prevent cronyism. There is also a shift in cultural and process management that must be considered, with the need of an established BIM committee who will be responsible for validating independent BIM Managers. The Implementing of BIM will require both vision and determination and must come in the form of a top down strategy from the Irish Government in order to ensure its success. However the reality is that this is highly unlikely, as the GCCC contracts would have to provide BIM procedures or an execution plan template, as part of the CWMF guidelines, which at present seems unlikely due to low tender prices been already achieved. There has encouragingly been recent interest from the Irish Government in regards to BIM, as can be seen from the recent CITA delegation who were invited to argue the business case of moving towards the BIM process. The Irish AEC needs to continue the push towards a better built future and study visible market place profits in other countries, which have been achieved by mandating BIM.

\section{References}

Arayici, Y., Coates, P., Koskela, L., Kagioglou, M., Usher, C. and O'Reilly, K. (2011). BIM adoption and implementation for architectural practices, Structural Survey, Vol. 29 No. 1, pp. 7-25.

Bachman, M. (2009). BIM's Effect on Design Culture, available atjhttp://www.di.net/articles/ archive/bims_effect_on_design_culture/ > (21/05/2012).

Business wire (2012). BIM Market to reach $\$ 6.5 B$ Worldwide by 2020, Forecasts Pike Research.

Department of Finance (2007). Capital Works Management Framework - Guidance Note for Public Works Contracts, Department of Finance.

Douglas, B., Arensman, M. S. and Mehmet, E. Ozbek (2012). Building Information Modeling and Potential Legal Issues, International Journal of Construction Education and Research, 8, 146-56.

Government Construction Client Group (GCCG) (2011). A report for the GCCG BIM Working Party Strategy Paper-Mar 11, UK Government.

Fogarty, Dan (2009). Contractor perspective of the new Irish Public Works Projects, Management Procurement and Law, Proceedings of the Institution of Civil Engineers, Feb 09, pp. 29-34 .

Hannele, K., Reijo, M., Tarja, M., Sami, P., Jenni, K. and Teija, R. (2012). Expanding uses of building information modelling in life-cycle construction projects, Work 41, pp. 114-119.

Henstridge (2011). Construction in the UK and Ireland on the mend, but recovery is slow and unsteady, The European Business Review.

McAuley, B., Hore, A. V. and West, R. (2012). Use of BIM in responding to Low Carbon Construction Innovations: An Irish Perspective, Proceedings of the Joint CIB International Conference on Management of Construction: Research to Practice, Montreal, Jun 26-29th.

McAuley, B., Hore, A. V. and West, R. (2012). Implementing of Building Information Modelling in Public Works Projects, Proceedings of the 9th European Conference on Product and Process Modelling, Reykjavik, July 25-27th, 2012.

Nugent, A. (2012). No output increase until 2014: but opportunities in the greed sector, Irish Construction Magazine, pp. 11, April / May.

Wong, A. K. D., Wong, F. K. W. and Nadeem, A. (2009). Comparative Roles of Major Stakeholders for the Implementation of BIM in Various Countries, Integration And Collaboration 3, Changing Roles.

Wren, T. (2011). The Irish Works Contract Major Forms Contract 3: Damage. Loss and Inquiry Analysis, available at www.tomwren.ie/GCCC_3.pdf> accessed (14/03/ 2012). 